\title{
COMPARISON OF OXIDATIVE STRESS AND TELOMERE DYSFUNCTION IN HYPERTENSION PATIENTS
}

\author{
Prashanth B. V1, Subhash Giri², Yashaswini P3
}

${ }_{1}^{1}$ Senior Resident, Department of General Medicine, KIMS, Bangalore, Karnataka, India.

2 Professor, Department of General Medicine, UCMS and GTBH, New Delhi, India.

3Postgraduate Student, Department of Pharmacology, BMCRI, Bangalore, Karnataka, India.

\section{BACKGROUND}

ABSTRACT

Hypertension is one of the leading causes of cardiovascular disease death. Hypertension is associated with oxidative stress. Oxidative stress causes telomere dysfunction. In this study, I have compared telomere dysfunction and oxidative stress among hypertensive patients and age sex matched healthy controls.

Aims and Objectives- Oxidative stress is the unifying pathophysiological mechanism responsible for ageing and age-related diseases like diabetes, hypertension, atherosclerosis etc. Oxidative stress is defined as increase in the intracellular concentration of reactive oxygen species. Telomeres are specialised DNA-protein structures located at the ends of eukaryotic chromosomes, whose length is progressively reduced in most somatic cells during ageing. Insulin resistance and oxidative stress are associated with accelerated telomere attrition, implicated in the biology of ageing/ in ageing-related disorders including hypertension. We hypothesised higher oxidative stress, measured by Malondialdehyde (MDA) and Glutathione-S transferase (GST) associated with telomere dysfunction in hypertensive patients. So, a case control study was undertaken to study the dysfunction of telomere in these patients.

\section{MATERIALS AND METHODS}

The study was conducted at a tertiary care hospital in Delhi, India, which includes 40 hypertensive male patients (aged 45 - 65 years) and equal number of age-matched healthy controls. Based on convenience, we have taken 40 patients in each group. We performed biophysical parameters check, routine and special investigations like measurement of MDA levels (Ohkawa method), GST levels (Mozer method). In all subjects, telomere length was measured by real time PCR from the DNA isolated from leucocytes (Cawthon's method) and telomerase activity was measured by measuring hTERT mRNA expression by RT-PCR, Taqman methodology from leucocytes.

\section{RESULTS}

It was observed that the mean MDA level in cases and controls were $0.90 \pm 0.30$ and $0.65 \pm 0.18$ respectively ( $p=0.01$ ). The mean GST level in cases and controls were found to be $0.68 \pm 0.17$ and $1.02 \pm 0.32 \mu \mathrm{mol} / \mathrm{mL} / \mathrm{min}$ respectively (p=0.001). We also found that mean telomere length was found to be shorter in hypertensive patients ( $8.17 \pm 1.26 \mathrm{~kb})$ as compared to controls $(10.47 \pm 1.79$ $\mathrm{kb})$ respectively $(\mathrm{p}<0.001)$. The expression of hTERT (mean $\Delta$ ct ratio) of cases $(-0.18)$ was higher as compared to control $(16.17)$.

\section{CONCLUSION}

It was observed that there was a significant shortening of telomere length with higher oxidative stress in hypertensive patients as compared to healthy control.

\section{KEY WORDS}

Oxidative Stress, Telomere Length, Telomerase, Hypertension.

HOW TO CITE THIS ARTICLE: Prashanth BV, Giri S, Yashaswini P. Comparison of oxidative stress and telomere dysfunction in hypertension patients. J. Evolution Med. Dent. Sci. 2018;7(26):3017-3022, DOI: 10.14260/jemds/2018/678

\section{BACKGROUND}

One of the leading causes for burden of disease is said to be hypertension. High blood pressure accounts for 7.6 million deaths (13 to $15 \%$ of total death) and 92 million disability adjusted life years (DALY). ${ }^{1}$ Prevalence of hypertension is $65.4 \%$ among elderly people of $>60$ years and it increases with the age. ${ }^{2}$ Major risk factors for hypertension are obesity and weight gain, if patient is having history of cardiac and renal disease the risk is doubled.

'Financial or Other Competing Interest': None.

Submission 14-05-2018, Peer Review 10-06-2018,

Acceptance 16-06-2018, Published 25-06-2018.

Corresponding Author:

Prashanth B. V,

C/o. S. R. Pandurangappa,

\#49, Sonnappa Layout, Next To Indian Express (L/o),

Vidyaranyapura Post, Bangalore-560097, Karnataka, India.

E-mail: prashi99@gmail.com

DOI: $10.14260 /$ jemds $/ 2018 / 678$
Genetic and environmental factors, low physical activity, psychosocial stress, alcohol consumption, low dietary intake of potassium and calcium, high salt intake contribute to prevalence of hypertension. ${ }^{3}$

Since last six decades, prevalence of hypertension increased from 2 to $15 \%$ in rural and from 2 to $25 \%$ in urban residents in India. By the end of 2020, prevalence of hypertension will be $159.46 / 1000$ population. ${ }^{4}$

One of the pathogenesis responsible for hypertension is Oxidative stress. Oxidative stress also leads to diseases like diabetes, hypertension and atherosclerosis. 5

Oxidative stress is defined as increase in the intracellular concentration of reactive oxygen species (ROS). ROS are generated during regular metabolism because of incomplete oxygen reduction in the mitochondrial electron chain and plays an important role in pathophysiology of hypertension.

According to recent studies the endothelial injury increases production of pro-oxidants such as hydrogen peroxide, superoxide anion and decreases synthesis of nitric 
oxide and also decreases levels of antioxidants. Oxidative stress is associated with inflammation, endothelial dysfunction hypertrophy, apoptosis, cell migration, fibrosis and angiogenesis in relation to vascular remodelling of hypertension. ${ }^{6}$

During ageing telomeres length is reduced in most of somatic cells and short telomeres are found in atherosclerotic plaque and also in myocardial tissue in patients with cardiac hypertrophy and end-stage heart failure. These telomeres are DNA proteins located at ends of eukaryotic chromosomes, shortening of telomere length detected in patient's WBCs with hypertension and diabetes mellitus.

Telomere attrition in leukocytes associated with oxidative stress and insulin resistance; both are also implicated in the biology of ageing and in ageing-related disorders including hypertension. ${ }^{7}$ Recently, it has been hypothesised that insulin resistance and oxidative stress is responsible for genesis of essential hypertension. It has been hypothesised that telomere length and telomerase activity may get reduced in hypertensive patients.

\section{Aim}

To study the comparison between oxidative stress with telomere dysfunction in patients of hypertension.

\section{Objectives}

\section{Primary Objectives}

- To compare telomere length and telomerase activity in hypertensive male patients aged between 45 and 65 years with age-matched healthy controls.

- To compare the level of oxidative stress in hypertensive male patients aged between 45 and 65 years with agematched healthy controls.

\section{Secondary Objective}

- To study the correlation between oxidative stress (Malondialdehyde, Glutathione S Transferase) with telomere dysfunction (telomere length and telomerase activity) in hypertensive male patients.

\section{MATERIALS AND METHODS}

\section{Study Design}

It was case-control study (1: 1 ) comprising of 80 subjects (40 cases and 40 controls), which was carried out in Department of Medicine and Biochemistry in University College of Medical Sciences (UCMS) and Guru Teg Bahadur Hospital (GTBH) from November 2014 to April 2016.

Forty male patients of essential hypertension of age 4565 yrs. from hypertensive clinic and Medicine OPD of GTB hospital who satisfy the inclusion and exclusion criteria were recruited for study. Equal number of age matched clinically healthy males were recruited as control from hospital staff, healthy unrelated attendants of patients. After getting written informed consent from both cases and controls, detailed history, general physical examination, systemic examination, electrocardiogram, fundus examination, routine blood examination and urine examination was done in all cases and controls.

$3 \mathrm{~mL}$ of blood is collected in EDTA vial from both cases and controls for measurement of telomere length and telomerase activity. Another $3 \mathrm{~mL}$ of blood is collected in plain vial, centrifuged at $3000 \mathrm{rpm}$ and serum is separated to measure MDA and GST activity. Telomere length was measured by Real Time Polymerase Chain Reaction (RT-PCR). ${ }^{8}$ As hTERT is as component of telomerase enzyme, measuring hTERT expression gives an idea of telomerase activity in samples. HTERT mRNA expressions were estimated by reverse transcriptase-PCR (RT-PCR) and Taqman methodology.9 MDA levels are a quantitative measure of lipid peroxides. Estimation of blood lipid peroxidation was done by measuring MDA levels as described by Ohkawa et al.10 Glutathione S-transferase (GST) was measured by spectrophotometric assay according to the method of Mozer et al. ${ }^{11}$

\section{Inclusion Criteria \\ Cases}

Patients having systolic blood pressure $\geq 140$ and diastolic blood pressure $\geq 90$ according to JNC 7 th criteria were taken as cases.

\section{Exclusion Criteria}

Patients with following Diseases were excluded from Study-

- $\quad$ Diabetes mellitus (FBS $>126 \mathrm{mg} / \mathrm{dL}$ and post prandial blood sugar $>200 \mathrm{mg} / \mathrm{dL}$ ).

- Impaired fasting glucose (Blood sugar 100 - $125 \mathrm{mg} / \mathrm{dL}$ ).

- Acute or chronic liver disease [Serum aminotransferase $>3$ fold (>120 IU/L)].

- Acute or chronic renal disease (Serum creatinine levels $>1.5 \mathrm{mg} / \mathrm{dL}$ ).

- Acute and chronic infectious diseases.

- Malignancy.

- $\quad$ Smokers (> 5 Cigarettes per day) Alcoholics (> 21 Units per week).

- Secondary hypertension.

- Patients with Coronary artery disease.

- Collagen vascular diseases.

\section{Controls}

Equal number of age-matched clinically healthy males without hypertension were enrolled. Controls were hospital staff, healthy unrelated attendants of patients.

\section{Sample Size}

Based on convenience, we have taken 40 each group.

\section{Statistical Analysis \\ Tests for Significance}

Comparison between two groups were obtained by unpaired t-test for all quantitative parameters and by chi-square/ Fisher's exact test for qualitative parameters. Since MDA and GST parameters were following non-Gaussian distribution, log transformation has been applied to normalise the data and to apply the appropriate parametric tests. The whole analysis was carried out by SPSS v20.0. A p-value $<0.05$ was considered significant.

\section{RESULTS}

The important results of our study were-

\section{Age Distribution}

Mean age of cases and controls were $54.90( \pm 5.80)$ years and $54.80( \pm 5.52)$ years respectively. All the study subjects were 
males because oestrogen acts as stimulatory factor on telomerase activity, which may act as confounding factor for telomerase activity. Therefore, we included only male subjects in our study.

\section{Anthropometric Profile}

Mean waist hip ratios (WHR) of cases and controls were 0.93 $( \pm 0.02)$ and $0.89( \pm 0.04)$ respectively $(p=0.001)$. Mean waist circumference (WC) among cases and controls were $90.40( \pm 4.36) \mathrm{cm}$ and $80.60( \pm 4.71) \mathrm{cm}$ respectively $(\mathrm{p}=0.001)$.

\begin{tabular}{|c|c|c|c|}
\hline Parameters & $\begin{array}{c}\text { Cases (n=40) } \\
\text { Mean } \pm \text { SD }\end{array}$ & $\begin{array}{c}\text { Controls (n=40) } \\
\text { Mean } \pm \text { SD }\end{array}$ & P value \\
\hline Age (years) & $54.90( \pm 5.80)$ & $54.80( \pm 5.52)$ & 0.937 \\
\hline WHR $^{*}$ & $0.93( \pm 0.02)$ & $0.889( \pm 0.04)$ & 0.001 \\
\hline WC (in cm) & $90.40( \pm 4.36)$ & $80.60( \pm 4.71)$ & 0.001 \\
\hline SBP in mmHg* & $145.93( \pm 9.14)$ & $128.9( \pm 5.10)$ & 0.001 \\
\hline DBP in mmHg* & $84.33( \pm 5.74)$ & $76.23( \pm 5.57)$ & 0.001 \\
\hline \multicolumn{4}{|c|}{ Baseline Comparison between Cases and Controls } \\
\hline
\end{tabular}

Legend; above table consists of baseline comparison of age, waist circumference, waist-hip ratio, blood pressure among cases and controls.

${ }^{*} \mathrm{p}<0.005$ is significant.

Abbreviations: WHR $=$ Waist-Hip Ratio; $W C=$ Waist Circumference; SBP= Systolic Blood Pressure; DBP= Diastolic Blood Pressure.

\section{Serum Lipid Profile among Cases and Controls}

The mean total cholesterol in cases and controls was 159 $( \pm 20.95) \mathrm{mg} / \mathrm{dL}$ and $142.48( \pm 11.97) \mathrm{mg} / \mathrm{dL}$ respectively $(\mathrm{p}=0.001)$. The mean triglycerides value among cases and controls was $132.45( \pm 22.93) \mathrm{mg} / \mathrm{dL}$ and $100.53( \pm 6.43)$ $\mathrm{mg} / \mathrm{dL}$ respectively $(\mathrm{p}=0.001)$. The mean LDL values in cases and controls was found to be $110.53( \pm 13.2) \mathrm{mg} / \mathrm{dL}$ and $78.95( \pm 17.7) \mathrm{mg} / \mathrm{dL}$ respectively $(\mathrm{p}=0.001)$. The mean HDL in cases was $36.60( \pm 4.32) \mathrm{mg} / \mathrm{dL}$ and in controls was 40.88 $( \pm 6.29) \mathrm{mg} / \mathrm{dL}(\mathrm{p}=0.001)$. The mean VLDL values in cases and controls was $22.75( \pm 6.21) \mathrm{mg} / \mathrm{dL}$ and $18.25( \pm 3.35)$ $\mathrm{mg} / \mathrm{dL}$ respectively $(\mathrm{p}=0.001)$.

\begin{tabular}{|c|c|c|c|}
\hline Parameters & $\begin{array}{c}\text { Cases (n=40) } \\
\text { mean } \pm \text { SD }\end{array}$ & $\begin{array}{c}\text { Controls (n=40) } \\
\text { mean } \pm \text { SD }\end{array}$ & P value \\
\hline $\begin{array}{c}\text { Total cholesterol } \\
(\mathrm{mg} / \mathrm{dL})^{*}\end{array}$ & $159( \pm 20.95)$ & $142.48( \pm 11.97)$ & 0.001 \\
\hline $\begin{array}{c}\text { Triglycerides } \\
(\mathrm{mg} / \mathrm{dL})^{*}\end{array}$ & $132.45( \pm 22.93)$ & $100.53( \pm 6.43)$ & 0.001 \\
\hline $\begin{array}{c}\text { LDL cholesterol } \\
(\mathrm{mg} / \mathrm{dL})^{*}\end{array}$ & $110.53( \pm 13.2)$ & $78.95( \pm 17.7)$ & 0.001 \\
\hline $\begin{array}{c}\text { HDL cholesterol } \\
(\mathrm{mg} / \mathrm{dL})^{*}\end{array}$ & $36.60( \pm 4.32)$ & $40.88( \pm 6.29)$ & 0.001 \\
\hline $\begin{array}{c}\text { VLDL cholesterol } \\
(\mathrm{mg} / \mathrm{dL})^{*}\end{array}$ & $22.75( \pm 6.21)$ & $18.25( \pm 3.35)$ & 0.001 \\
\hline $\begin{array}{c}\text { Baseline Comparison of Serum Lipid Profile among Cases } \\
\text { and Controls }\end{array}$ \\
\hline
\end{tabular}

Legend; above table consists of serum lipid profile among cases and controls.

${ }^{*} \mathrm{p}<0.05$ is significant.
Abbreviations: VLDL= Very Low Density Cholesterol; LDL= Low Density Cholesterol; HDL= High Density Cholesterol.

\section{Special Parameters of our Study}

\section{Telomere Length and Telomerase Activity}

The telomere length was measured in both cases and controls. We found that mean telomere length in cases was shorter $(8.17 \pm 1.26 \mathrm{~kb})$ as compared to controls $(10.47 \pm 1.79$ $\mathrm{kb})$. This difference was significant statistically $(\mathrm{p}=0.001)$.

\begin{tabular}{|c|c|c|c|}
\hline Parameter & $\begin{array}{c}\text { Cases (n=40) } \\
\text { mean } \pm \text { SD }\end{array}$ & $\begin{array}{c}\text { Controls (n=40) } \\
\text { mean } \pm \text { SD }\end{array}$ & P value \\
\hline $\begin{array}{c}\text { Telomere } \\
\text { length* (in kb) }\end{array}$ & $8.17 \pm 1.26$ & $10.47 \pm 1.79$ & 0.001 \\
\hline \multicolumn{3}{|c|}{ Telomere Length among Cases and Controls } \\
\hline
\end{tabular}

Legend; above table consists of telomere length among cases and controls.

${ }^{*} \mathrm{p}<0.05$ is significant.

Abbreviations: $\mathrm{Kb}=$ kilobase pairs.

We also calculated the odds ratio for telomere length and hypertension. After statistical analysis we found that when telomere length decreases by one unit (one $\mathrm{kb}$ ), risk of hypertension increases by 0.384 times (odds ratio) with CI (0.253 - 0.583).

\begin{tabular}{|c|c|c|c|c|}
\hline & B & P value & $\begin{array}{c}\text { Odds } \\
\text { Ratio }\end{array}$ & $\begin{array}{c}\text { 95\% Confidence } \\
\text { Interval (CI) }\end{array}$ \\
\hline $\begin{array}{c}\text { Telomere } \\
\text { Length }\end{array}$ & -0.957 & $<0.001$ & 0.384 & $0.253-0.583$ \\
\hline \multicolumn{3}{|c|}{ Odds Ratio (OR) and 95\% Confidence Interval (CI) of } \\
Telomere Length with Hypertension
\end{tabular}

Legend; above table consists of odds ratio and 95\% confidence interval of telomere length with hypertension.

$\mathrm{P}<0.05$ is significant.

\section{Telomerase Activity}

We measured hTERT expression in cases and controls as an indicator for telomerase activity. The ratio of expression among cases and controls was calculated by $\Delta \Delta \mathrm{ct}$ method. The mean $\Delta$ ct of cases was -0.18 and that of controls was 16.17. This means expression of hTERT was almost $8 \times 10^{\wedge} 4$ times higher in cases as compared to controls.

\section{Oxidative Stress Markers Estimation}

\section{MDA Estimation and GST Level Estimation}

Each value of malondialdehyde (MDA) was multiplied by 100 and log was applied to find mean value. The mean MDA level estimation in cases was found to be $0.90( \pm 0.30)$, and in controls was $0.65( \pm 0.18)$ respectively. The difference between the two groups was significant statistically $(\mathrm{p}=0.01)$ Each value of glutathione S-transferase (GST) is multiplied by 100 and log was applied to find mean value. The mean GST level estimation in cases and controls was found to be 0.68 $( \pm 0.17) \quad \mu \mathrm{mol} / \mathrm{mL} / \mathrm{min}$ and $1.02 \quad \pm 0.32) \mu \mathrm{mol} / \mathrm{mL} / \mathrm{min}$ respectively. The difference between the two was significant statistically $(p=0.001)$. 


\begin{tabular}{|c|c|c|c|}
\hline Parameters & $\begin{array}{c}\text { Cases (n=40) } \\
\text { mean } \pm \text { SD }\end{array}$ & $\begin{array}{c}\text { Controls (n=40) } \\
\text { mean } \pm \text { SD }\end{array}$ & P value \\
\hline MDA levels* & $0.90 \pm 0.30$ & $0.65 \pm 0.18$ & 0.001 \\
\hline $\begin{array}{c}\text { GST levels in } \\
\mu \mathrm{mol} / \mathrm{mL} / \mathrm{min}^{*}\end{array}$ & $0.68 \pm 0.17$ & $1.02 \pm 0.32$ & 0.001 \\
\hline \multicolumn{3}{|c|}{ MDA and GST Levels in Cases and Controls } \\
\hline
\end{tabular}

Legend; above table consists of MDA and GST levels among cases and controls.

${ }^{*} \mathrm{p}<0.05$ is significant.

Abbreviations: $\mathrm{MDA}=$ Malondialdehyde; GST $=$ Glutathione $\mathrm{S}-$ Transferase.

Correlation between Oxidative Stress and Lipid Fractions with Telomere Length in all Subjects

We studied correlation between TL and oxidative stress in all subjects $(n=80)$. It was observed that the positive correlation exists between TL and GST ( $\mathrm{r}=0.504)$, which was statistically significant $(p=0.001)$, while a negative correlation was observed between TL and MDA. We also observed a positive correlation between TL and HDL; however, a negative correlation was observed between TL and other lipid fractions like LDL, TG and total cholesterol.

\begin{tabular}{|c|c|c|c|}
\hline Variable & R value & P value & Significance \\
\hline MDA & -0.205 & 0.068 & Not Significant \\
\hline GST & 0.504 & 0.001 & Significant \\
\hline HDL & 0.347 & 0.002 & Significant \\
\hline LDL & -0.405 & 0.001 & Significant \\
\hline TG & -0.415 & 0.001 & Significant \\
\hline $\begin{array}{c}\text { Total } \\
\text { Cholesterol }\end{array}$ & -0.235 & 0.036 & Significant \\
\hline $\begin{array}{c}\text { Pearson's Correlation Coefficient between Telomere } \\
\text { Length, Oxidative Stress and Lipid Profile in all Subjects } \\
\text { (n= 80) }\end{array}$ \\
\hline
\end{tabular}

Legend; above table consists of correlation coefficient between telomere length, MDA, GST, HDL, LDL, TG and total cholesterol in all subjects.

Abbreviations: MDA= Malondialdehyde; GST= Glutathione STransferase; HDL= High Density Lipoprotein; LDL= Low Density Lipoprotein; TG= Triglycerides.

\section{DISCUSSION}

In this case control, age matched study 80 subjects ( 40 cases and 40 controls) were recruited after getting approval from the Institutional Ethical Committee. Detailed history captured, clinical examination conducted, and blood investigations were carried out in all subjects including telomere length, telomerase activity, oxidative stress markers like MDA levels and GST levels. Comparison of telomere status (TL and telomerase activity) and oxidative stress (MDA and GST levels) was studied in hypertensive patients.

\section{Demographic Profile}

Our study included male subjects between 45 and 65 years of age. Female subjects were not included in our study due to stimulatory effect of oestrogen on telomerase activity, which may alter telomere length. ${ }^{12}$

\section{Anthropometric Profile}

Mean WHR was found to be higher in cases as compared to controls and this difference was found to be statistically significant $(\mathrm{p}=0.001)$. We also found out that mean waist circumference was higher in cases as compared to controls. The difference between the two groups was significant statistically $(p=0.001)$. We observed that central obesity was more among cases than controls.

Our finding was consistent with study done by Rentoukas et al in patients with metabolic syndrome in 2012.13 They studied on 38 patients with metabolic syndrome consisting of 20 (52.6\%) hypertensive patients, 20 (38.5\%) diabetic subjects with age and sex matched healthy volunteers. They found that waist circumference in patients with metabolic syndrome was $129( \pm 15.8) \mathrm{cm}$ and in controls was 114 $( \pm 17.6) \mathrm{cm}$.

The derangement of cholesterol fractions was higher among cases. The total cholesterol was found to be higher in cases as compared to controls $(\mathrm{p}=0.001)$. The mean triglycerides was higher in cases as compared to controls. The difference between the two was significant statistically $(p=0.001)$. The mean LDL was higher in cases as compared to controls $(p=0.001)$. The mean VLDL was higher in cases as compared to controls $(p=0.001)$. The mean HDL was lower among cases as compared to controls. The difference between the two groups was statistically significant $(\mathrm{p}=0.001)$.

Our result shows that dyslipidaemia was higher among hypertensive patients. We earlier reported that central obesity was also higher among cases. As there is an association of central obesity with dyslipidaemia, the similar finding has been recorded in this study.

Our findings are consistent with Osuji et al on serum lipid profile of 250 newly diagnosed hypertensive patients with equal number of age and sex matched healthy controls in Nnewi, south east Nigeria in 2012. They found that mean total cholesterol, triglycerides, LDL levels, BMI, WC, WHR and FBS were significantly higher in cases as compared to healthy controls. They found that mean WC among cases and controls was $96.4( \pm 13.4)$ and $90.8( \pm 10.8)$ respectively, and the mean BMI among cases and control was $28.8( \pm 5.8)$ and 26.7 $( \pm 4.4) \mathrm{kg} / \mathrm{m}^{2}$ respectively. They found that mean total cholesterol among cases and controls was $4.83( \pm 0.95)$ and $4.15( \pm 0.57) \mathrm{mmol} / \mathrm{L}$ respectively. The mean LDL among cases and controls was $3( \pm 0.82)$ and $2.44( \pm 0.53) \mathrm{mmol} / \mathrm{L}$ respectively. The mean triglycerides among cases and controls was $1.23( \pm 0.32)$ and $1.10( \pm 0.24) \mathrm{mmol} / \mathrm{L}$ respectively. ${ }^{14}$

\section{Special Parameters of our Study Telomere Length}

In this study, hypertensive subjects had shorter telomere length $(8.17 \pm 1.26)$ as compared to controls $(10.47 \pm 1.79)$. Few investigators had found similar results of shortening of telomere length among hypertensive patients.

Bupatiraju et al in 2012 studied 96 hypertensive (35 - 70 years) and 98 normal subjects (30 - 70 years) in Osmania University of Hyderabad and found that relative telomere length in hypertensive individuals was significantly shorter when compared to normal individuals $(\mathrm{p}<0.001) .{ }^{15}$

Yang et al in 2009 studied 388 Chinese hypertensive subjects and 379 normal individuals and found that average telomere length ratio between hypertensive and normotensive subjects was 0.57 and 0.67 respectively $(\mathrm{p}=0.001) .^{16}$ 
Das et al in 2009 studied 47 hypertensive individuals and 37 normal subjects in Mumbai and found that relative telomere length in hypertensive patients was significantly shorter as compared to normal individuals $(\mathrm{p}<0.001) .{ }^{17}$

\section{Telomerase Activity}

In our study, telomerase activity was calculated by hTERT mRNA expression. We found that telomerase activity was significantly higher in cases as compared to controls.

In hypertensive patients, chronic inflammation is associated with proliferation of inflammatory cells like lymphocytes. The telomerase expression is increased in rapidly proliferating cells. In our study, we measured telomerase activity in lymphocytes and we found out that telomerase activity was higher in hypertensive patients as compared to healthy controls.

Our findings are consistent with Rentoukas et al who studied telomerase activity in peripheral blood mononuclear cells in patients with metabolic syndrome in 2012 in Greece. They found that telomerase activity was significantly elevated in patients with metabolic syndrome as compared to healthy subjects. ${ }^{13}$

\section{Oxidative Stress Markers Level Estimation MDA Levels}

We found that MDA level, a marker of lipid peroxidation was significantly higher in hypertensive patients as compared to healthy individuals $(\mathrm{p}=0.001)$. Similar findings of higher oxidative stress among hypertensive patients have been observed by few investigators.

Armas et al in 2007 studied on MDA levels in 42 hypertensive subjects and 21 healthy individuals in Venezuela and found that serum concentration of MDA was higher in hypertensive patients as compared to healthy controls. ${ }^{18}$

Tandon et al in 2005 studied on oxidative stress in 50 essential hypertension patients and 20 healthy subjects in Varanasi and found that mean serum malondialdehyde levels were higher $(0.33 \mathrm{mmol} / \mathrm{L})$ in hypertensive patients as compared to healthy controls $(0.21 \mathrm{mmol} / \mathrm{L}){ }^{19}$

\section{GST Activity}

Antioxidant levels as measured by GST were lower in hypertensive subjects (representative of higher oxidative stress). The mean GST activity was lower among cases as compared to controls. We found significant difference between the two groups $(\mathrm{p}=0.001)$.

Our findings are consistent with Marinho et al, who studied on GST activity in 94 hypertension patients and 207 healthy subjects in 2005 in Portugal. Plasma GST activity was determined spectrophotometrically. They found that GST activity was markedly decreased in hypertension patients as compared to healthy controls. ${ }^{20}$

\section{Correlation between Oxidative Stress and Lipid Fractions with Telomere Length in all Subjects}

We also studied correlation between TL and oxidative stress in all subjects. We observed that a positive correlation existed between TL and GST $(r=0.504, p=0.001)$. It was depicted in this study that there is an inverse correlation between oxidative stress and telomere length.
We also studied correlation between TL and various lipid fractions in all subjects and we found that there was a positive correlation between TL and HDL, which was statistically significant $(r=0.347, p=0.002)$. We also observed a negative correlation between $\mathrm{TL}$ and other fractions of lipids like LDL ( $\mathrm{r}=-0.405, \mathrm{p}=0.001)$, TG $(\mathrm{r}=-0.415 \mathrm{p}=0.001)$, total cholesterol $(r=-0.235, p=0.036)$ which was statistically significant. This analysis shows that dyslipidaemia has inverse correlation with telomere length.

In our study, telomere dysfunction (as measured by TL and telomerase activity) has been found to be higher among cases as compared to controls. Similarly, oxidative stress was found to be higher among hypertensive patients as compared to healthy controls. We studied correlation between oxidative stress and lipid fraction with telomere length in all the subjects. We observed an inverse correlation between oxidative stress and telomere dysfunction. Additionally, we observed that telomere dysfunction had an inverse relation to dyslipidaemia.

\section{CONCLUSION}

In a case control study, it was observed that telomere length was shorter in hypertensive male patients. We also observed that telomerase activity was higher in hypertensive patients. It was observed that oxidative stress was higher in cases as compared to healthy controls. Further it was observed that the telomere length has positive correlation with antioxidants (GST) and HDL cholesterol, while a negative correlation was found with oxidative stress and bad cholesterol (LDL, TG, total cholesterol). Hence, telomere dysfunction was found to be associated with oxidative stress and dyslipidaemia in this study.

\section{REFERENCES}

[1] Lawes CM, Hoorn VS, Rodgers A, et al. Global burden of blood-pressure-related disease, 2001. Lancet 2008;371(9623):1513-8.

[2] Appel LJ, Brands MW, Daniels SR, et al. Dietary approaches to prevent and treat hypertension: a scientific statement from the American Heart Association. Hypertension 2006;47(2):296-308.

[3] Adrogué HJ, Madias NE. Sodium and potassium in the pathogenesis of hypertension. $\mathrm{N}$ Engl J Med 2007;356(19):1966-78.

[4] Association of Physicians of India. Indian guidelines on hypertension (I.G.H.) - III. 2013. J Assoc Phys India 2013;61(Suppl 2):6-36.

[5] Von Zglinicki T, Bürkle A, Kirkwood TB. Stress, DNA damage and ageing - an integrative approach. Exp Gerontol 2001;36(7):1049-62.

[6] Khan S, Chuturgoon AA, Naidoo DP. Telomeres and atherosclerosis. Cardiovasc J Afr 2012;23(10):563-71.

[7] Balasubramanyam M, Adaikalakoteswari A, Monickaraj SF, et al. Telomere shortening \& metabolic/vascular diseases. Indian J Med Res 2007;125(3):441-50.

[8] Cawthon RM. Telomere measurement by quantitative PCR. Nucleic Acids Res 2002;30(10):e47.

[9] Kirkpatrick KL, Clark G, Ghilchick M, et al. hTERT mRNA expression correlates with telomerase activity in human breast cancer. Eur J Surg Oncol 2003;29(4):321-6. 
[10] Ohkawa H, Ohishi N, Yagi K. Assay for lipid peroxides in animal tissues by thiobarbituric acid reaction. Anal Biochem 1979;95(2):351-8.

[11] Mozer TJ, Tiemeier DC, Jaworski EG. Purification and characterization of corn glutathione S-transferase. Biochemistry 1983;22(5):1068-72.

[12] Stindl R. Tying it all together: telomeres, sexual size dimorphism and the gender gap in life expectancy. Med Hypotheses 2004;62(1):151-4.

[13] Rentoukas E, Tsarouhas K, Kaplanis I, et al. Connection between telomerase activity in PBMC and markers of inflammation and endothelial dysfunction in patients with metabolic syndrome. PLoS One 2012;7(4):e35739.

[14] Osuji CU, Omejua EG, Onwubuya EI, et al. Serum lipid profile of newly diagnosed hypertensive patients in nnewi, South-East Nigeria. Int J Hypertens 2012;2012:710486.

[15] Bhupatiraju C, Saini D, Patkar S, et al. Association of shorter telomere length with essential hypertension in Indian population. Am J Hum Biol 2012;24(4):573-8.
[16] Yang Z, Huang X, Jiang H, et al. Short telomeres and prognosis of hypertension in a Chinese population. Hypertension 2009;53(4):639-45.

[17] Das B, Pawar N, Saini D, et al. Genetic association study of selected candidate genes (ApoB, LPL, Leptin) and telomere length in obese and hypertensive individuals. BMC Med Genet 2009;10:99.

[18] Armas-Padilla MC, Armas-Hernández MJ, SosaCanache B, et al. Nitric oxide and malondialdehyde in human hypertension. Am J Ther 2007;14(2):172-6.

[19] Tandon R, Sinha MK, Garg H, et al. Oxidative stress in patients with essential hypertension. Natl Med J India 2005;18(6):297-9.

[20] Marinho C, Alho I, Arduíno D, et al. GST M1/T1 and MTHFR polymorphisms as risk factors for hypertension. Biochem Biophys Res Commun 2007;353(2):344-50. 